Version of Record: https://www.sciencedirect.com/science/article/pii/S092849311931118X

\title{
Optimization of a low pressure plasma process for fabrication of a Drug Delivery System (DDS) for cancer treatment.
}

Alibi Baitukha ${ }^{1}$, Iman Al-Dybiat ${ }^{2}$, Azadeh Valinataj-Omran², Jerome Pulpytel ${ }^{1}$, Marc Pocard², Massoud Mirshahi ${ }^{2}$ and Farzaneh Arefi-Khonsari ${ }^{1}$

1 Sorbonne Universités, UPMC Univ Paris 06, CNRS, Laboratoire Interfaces et Systèmes Electrochimiques, 4 place Jussieu, 75005, Paris, France

2 Sorbonne Paris Cité, UMR Université Paris 7, INSERM U965 Carcinose, Angiogenèse et Recherche Translationnelle, L'Hôpital Lariboisière, 41 Bd de la Chapelle 75010 Paris France.

\section{Abstract}

A low pressure ICP plasma setup was utilised to deposit thin organic barrier coatings on various substrates to fabricate DDS with encapsulated Carboplatin as a drug and Methylene Blue as a drug model. Choice of the substrates and optimal plasma parameters were discussed for the fabrication of DDS with required characteristics. Prepared thin films were analysed by FTIR, SEM, and the barrier properties were studied by measuring drug concentration released into the medium by UV-VIS and ICP-MS techniques. 


\section{Introduction}

Carboplatin is an anticancer platinum drug widely administered in clinical practice to treat different types of cancer $[1,2,3,4]$. By covalently binding to DNA strain which results in the formation of various defects in DNA molecule it forces the cell to undergo apoptotic death path [5]. Usually platinum drugs are systematically administered intravenously and because of nonselective treatment of normal and cancer cells it leads to many side effects and forces to dose limitation and decrease in efficiency [6]. In order to improve selective drug delivery for the cancer treatment it is necessary to develop new strategies and methods of extended and controlled drug delivery systems. A wide range of technologies are developed and applied [7, 8, $9,10]$, and one of the trending directions is the implantation of biodegradable systems that undergoes degradation through hydrolysis and enzymatic digestion of polymer matrix loaded with drug. Such drug delivery systems does not require surgical removal after depletion of loaded drug $[9,10]$. The choice of materials is limited to biocompatible ones. In order to achieve required physico-chemical properties, the material surface could be tailored by the procedures such as grafting $[13,14]$, or copolymerization $[15,16,17]$.

Biocompatible and resorbable collagen membranes are already widely used in post-surgery treatment to prevent postoperative digestive adhesion processes and intended to promote tissue regeneration. Such membranes represent an excellent base for drug delivery systems as already proven to be efficient in post-surgery treatment $[18,19]$. In our previous study we reported on successful application such membranes and preparation on their bases DDS [20] and in this study we are reporting on optimization of preparation parameters, tuning the kinetics of drug release, and investigating pros and cons of such membranes for DDS.

Plasma polymerization is a universal technique that allows to deposit films with variety of properties ranging from dense barrier films to soft cell repellent coatings, where film properties can be controlled and changed in situ $[21,22,23]$. By depositing plasma polymers on top of existing materials it is possible to add additional functions to the surface and control biological activity on it $[24,25]$. By encapsulating drugs in ultra-thin barrier films it is possible to modify biocompatible collagen membranes to be used as drug delivery systems [26]. In comparison to conventional wet chemical deposition processes, plasma enhanced CVD is a catalyst free, dry and solvent free process. Recent works show that plasma copolymerization of different organic precursors can be used to tailor specific physico-chemical properties on the surface of the films to control cell interactions on the interface $[27,28,29,30]$. Polyethylene glycol (PEG) is FDA approved material and an excellent candidate for drug delivery systems in the class of biodegradable polymers and was a choice of material in our previous research works with low pressure [31, 32] and atmospheric pressure plasma systems [33].

In our research we used a low pressure inductively coupled plasma assisted chemical vapour deposition system to evaluate the effectiveness of manufactured drug delivery system to deliver carboplatin drugs in vitro and in vivo.

\section{Experimental equipment}

\section{Materials}

Diethylene glycol dimethyl ether (diglyme, $134.17 \mathrm{~g} / \mathrm{Mol}, \mathrm{C}_{6} \mathrm{H}_{14} \mathrm{O}_{3}$, Sigma-Aldrich) was used as the precursor material and delivered into the reactor through bubbling in argon gas. 
Carboplatin (CBDCA, $150 \mathrm{mg} / 15 \mathrm{~mL}$, Hospira Inc) was used as antineoplastic (anticancer) drug and Methylene blue (MB) was used as model drug to measure the kinetics of drug release in this study. FDA approved Steralloy ${ }^{\mathrm{TM}}$ E-series hybrid elastomer (HAPCO) and collagen membranes (Biom'UP COVA+) of biological origin were used as substrates. Collagen comes as $100 \mu \mathrm{m}$ thick dried films, after placement in aqueous medium for 20 minutes it swells in volume, making it easy to handle and position on surfaces of different shapes. Steralloy ${ }^{\mathrm{TM}}$ elastomer biocompatible material [34] comes as liquid moulding compound consisting of two components. In comparison to collagen Steralloy has superior mechanical properties and nonswelling behaviour in aqueous mediums. Components of Steralloy prepolymers were mixed and casted onto smooth glass surface to form $100 \mu \mathrm{m}$ thick membranes. Components were kept under vacuum for several hours to degas before mixing and heated up to $50{ }^{\circ} \mathrm{C}$ for 1 hour after casting and subsequently peeled from the glass substrate.

\section{Inductively coupled plasma (ICP) setup}

Low pressure inductively coupled plasma (ICP) reactor is schematically illustrated in fig. 1. Operating pressure was set at 375 mTorr and controlled through adjusting argon gas flow rate and gate valve of turbomolecular pump. A $13.56 \mathrm{MHz}$ RF power supply was programmed to carry out deposition of a sequence of layers with varying density and thicknesses. This allowed us to automate multi-step deposition procedures to deposit composite films with different deposition parameters and fabricate films with alternating or gradually changing density, chemical composition and mechanical properties.

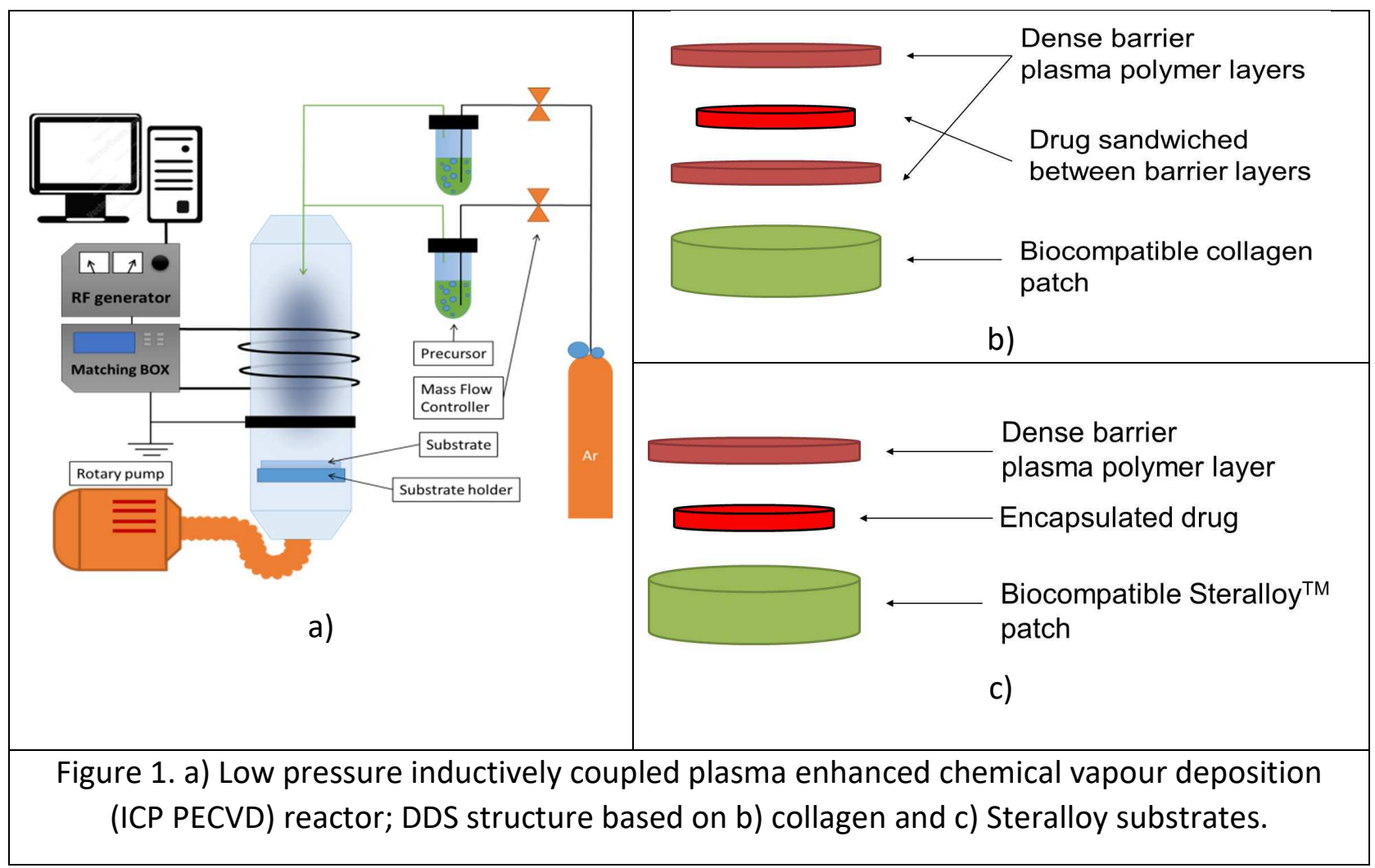


FTIR spectra were taken using VERTEX 70 (Bruker) in Attenuated Total Reflection (ATR) mode with germanium crystal as internal reflection element. Infrared absorption spectra were recorded in the range $700-4000 \mathrm{~cm}^{-1}$, with a resolution of $8 \mathrm{~cm}^{-1}$ and 100 repetitions. ATR correction of the baseline, $\mathrm{CO}_{2} / \mathrm{H}_{2} \mathrm{O}$ lines and the effect of the depth of penetration in ATR mode was performed in OPUS 6.5 software.

\section{FE-SEM}

Deposited films were studied by Field Emission Scanning Electron Microscopy (FE-SEM). FE-SEM images were taken using Zeiss Ultra 55 FEG SEM with GEMINI Column on gold coated surfaces by sputter coating (Cressinton sputter coater-108).

\section{Ellipsometry}

The refractive index and the thickness of the films deposited on Si substrates were measured by spectroscopic ellipsometry performed on a UV-IR (193-1690 nm) variable angle spectroscopic ellipsometer (VASE) M2000DI from Woollam at an incidence angle of $70^{\circ}$, and the data analysis was performed with the CompleteEASE software.

\section{ICP-MS}

The kinetics of carboplatin release into Dulbecco's Modified Eagle Medium (DMEM) culture cell medium (Thermo Fischer scientific, France) was measured by detecting Pt concentration using ICP-MS (Inductively Coupled Plasma Mass Spectrometry, Elan DRCe, Perkin Elmer ${ }^{\circledR}$ ). The mass bias was corrected with a certified reference material (Common Lead Isotopic Standard, SRM 981, NIST) using the standard bracketing technique [35].

\section{Optical spectroscopy}

The release of MB into DMEM medium was measured by UV-VIS spectrometer Ocean Optics Maya2000 Pro series, by following MB absorption peak at $665 \mathrm{~nm}$.

\section{DDS fabrication protocol}

The fabrication of DDS based on collagen takes several steps (fig.1, b): first covered with $1 \mu \mathrm{m}$ plasma polymerized barrier layer (this is done to prevent leaching of drug through the collagen), after placement of the drug on the barrier layer, it is encapsulated with the second plasma polymerized barrier layer. In the case of Steralloy films no need for the first step, as 100 $\mu \mathrm{m}$ of Steralloy film represents excellent barrier layer itself, with no swelling and no drug leaching through the patch.

\section{Results and discussion}

The placement of drugs on the surface of barrier coatings was carried out in a particular way, the solutions of carboplatin and MB were placed on the surface and subsequently let to be dried in a closed dust free area at room temperature. The measured Water Contact Angle (GBX Instruments) of drug solution on the smooth non-treated barrier coating surface is $65^{\circ}$, and 10 $\mu \mathrm{l}$ of drug solution forms a droplet with the base diameter of $3.5 \pm 0.3 \mathrm{~mm}$ (fig 2 , a). 


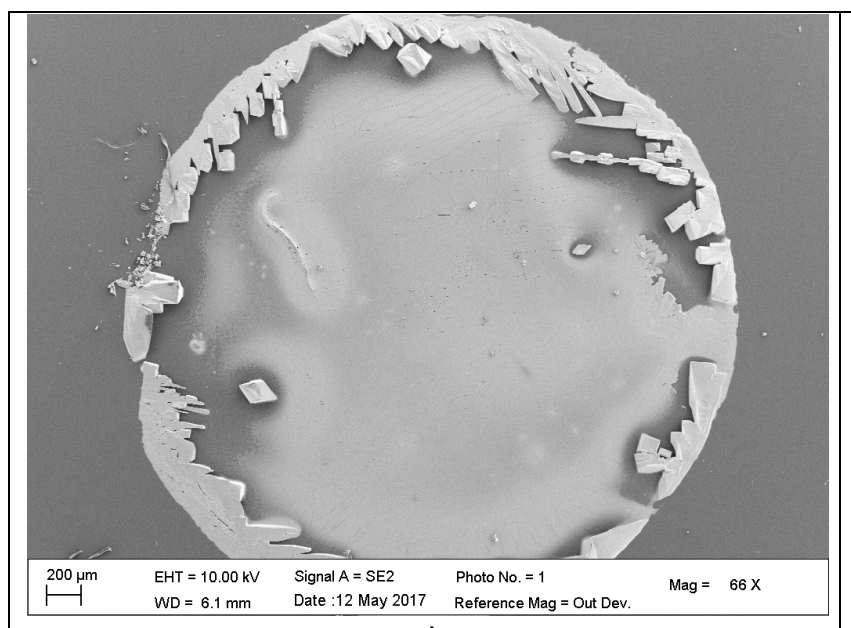

a)

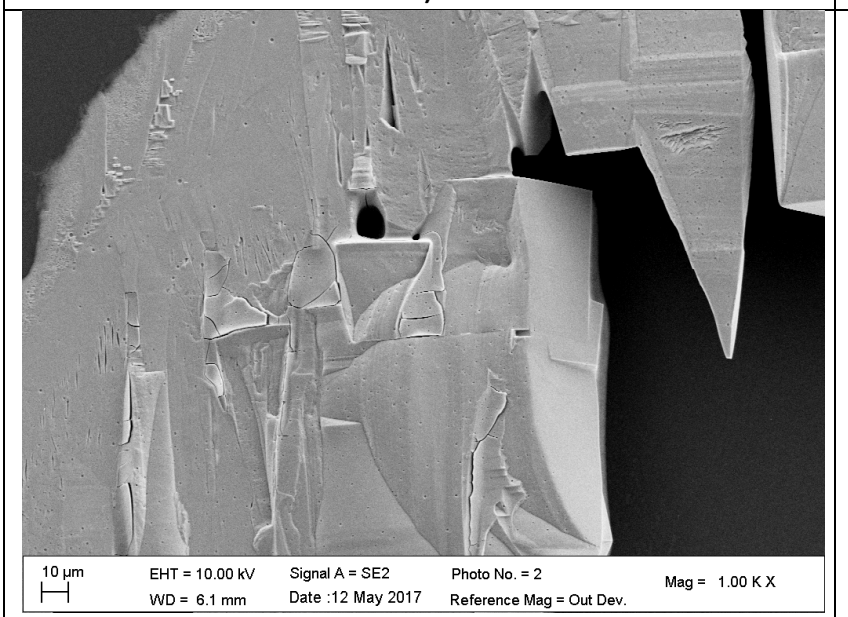

c)

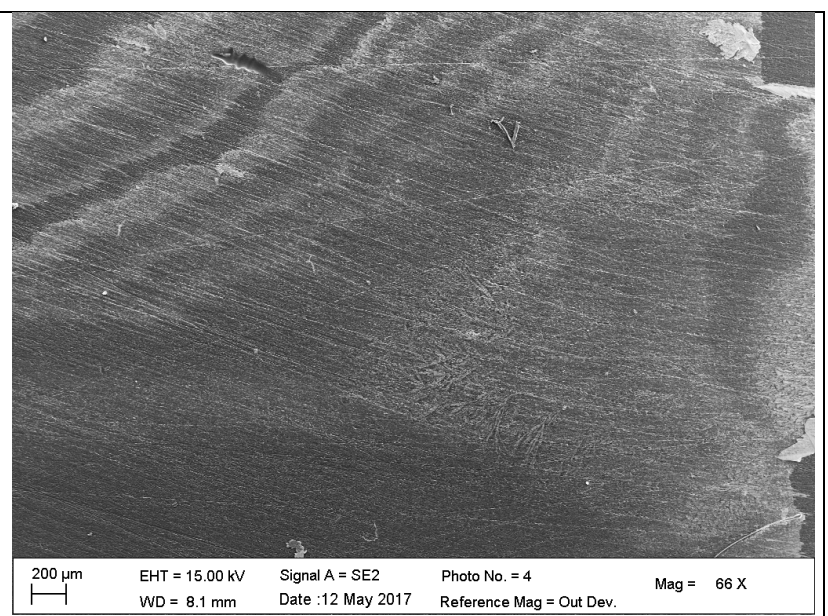

b)

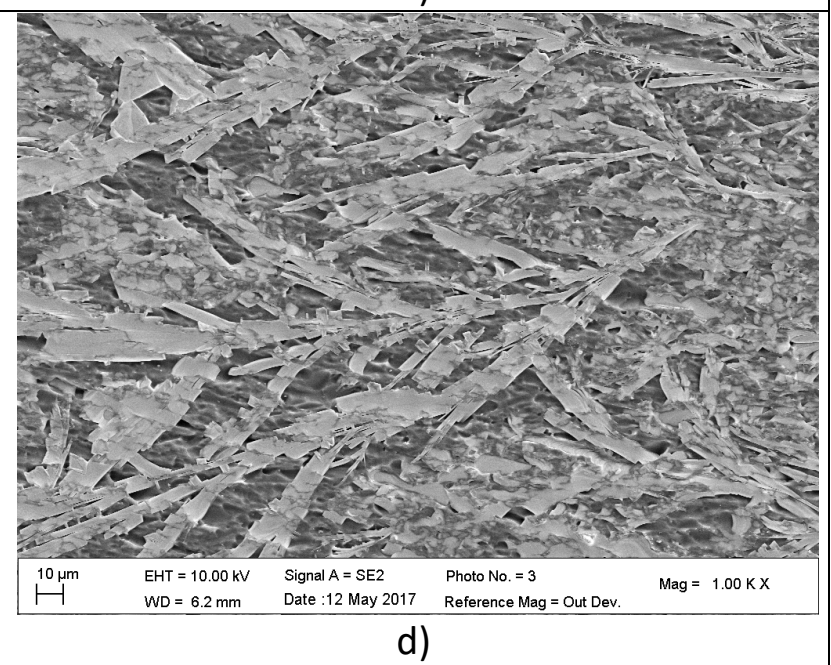

d)

Figure 2. SEM images of carboplatin crystals formed on the surface of Steralloy membranes: a) and c) on non-treated; b) and d) after air plasma treatment for $5 \mathrm{~min}$.

During the evaporation process, crystals of drug start to form on the edges and most of the drug remains as blocks on the circumference (fig.2 c). For flat 2D DDS models, where drug is sandwiched as a thin layer between barrier coatings, such localized concentration of the drug is not desirable. Treatment of barrier coatings were carried out to disperse the drug along the whole area of the membrane surface. An ICP air plasma treatment at 1 Torr for 5 min with an input power of $25 \mathrm{~W}$ would decrease the WCA down to $10^{\circ}$, and allow the spreading of the drug aqueous solution homogeneously across the surface of $1.5 \mathrm{~cm}^{2}$ membranes (fig. $2, \mathrm{~b}$ ) increasing the drug loaded area more than two orders of magnitude. The surface irregularities created by air plasma treatment induce crystal formation over the whole surface of the barrier coatings (fig.2, d).

In this work for the development of the DDS we used pulsed and continuous plasma polymerization of diglyme precursor to obtain either cell repellent coatings with the retention of the ether functions of the precursor or highly crosslinked polymers respectively.

OES spectra were used to identify the excited species in the plasma. In figure 2 OES spectrum is presented where the emission lines of different components in plasma are indicated. The emission lines were identified according to Pears and Gaydon [36] and Fabio Palumbo et al. [37]. 


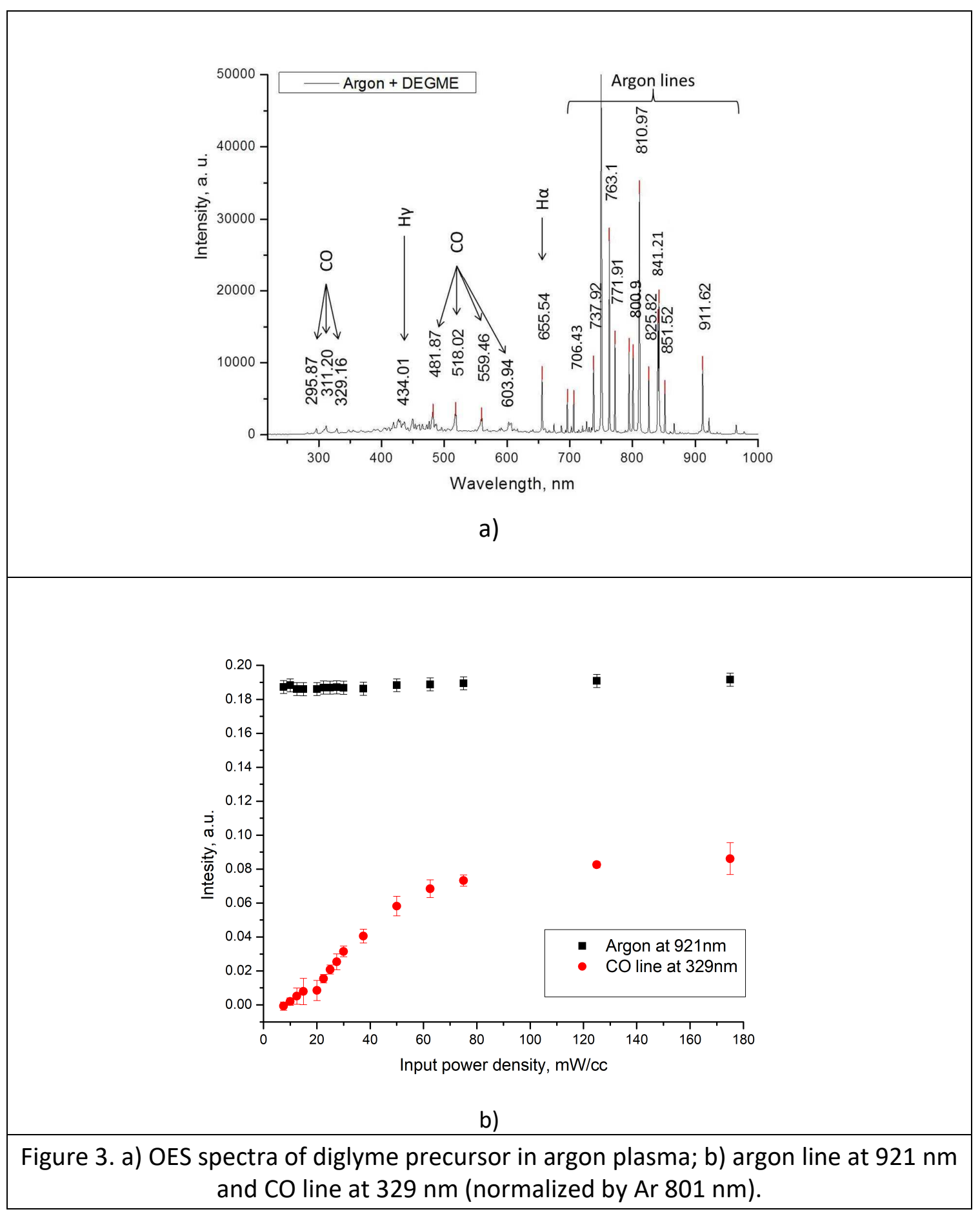

To determine the optimal power density to be delivered into the reactor, the intensities of the $\mathrm{CO}$ lines were analysed in comparison to Ar emission lines with the input power density varying in the range between 5 to $180 \mathrm{~mW} / \mathrm{cm}^{3}$. All peaks were normalized with respect to the $\mathrm{Ar}$ emission intensity at $801 \mathrm{~nm}$. Normalized Ar lines show no change with different input power densities. For $\mathrm{CO}$ lines it is a different case, with increasing input power more fragmentation of the diglyme precursor occurs leading to an increase of the emission of CO lines. Above 75 $\mathrm{mW} / \mathrm{cm}^{3}$ of input power density the intensities of CO lines reach a plateau (fig. 3, a), which indicates that most of the present diglyme precursor in the reactor are in a fragmented state. To deposit highly crosslinked dense films the effective input power in the reactor was $25 \mathrm{~W}$ (with discharge volume $400 \mathrm{~cm}^{3}$ power density equal to $62.5 \mathrm{~mW} / \mathrm{cm}^{3}$ ) at $100 \%$ of duty cycle in 
$5 \%$ mixture of diglyme precursor in working argon gas at 375 mTorr on $10 \mathrm{~cm}^{2}$ substrates placed downstream of plasma. The refractive index of these coatings was equal to $1.83 \pm 0.02$ (at $600 \mathrm{~nm}$ ) similar to diamond like carbon films [38] and indicates that these films represent an excellent candidates for DDS barrier films. W/FM or also known as Yasuda parameter [39] was calculated for our system and the energy input per monomer flow was $64 \mathrm{MJ} / \mathrm{kg}$, that points the deposition process takes place in the monomer deficient zone [40]. FTIR spectra of such films (fig. 4, black line) show no retention of C-O-C bonds $\left(1100 \mathrm{~cm}^{-1}\right)$ present in the precursor molecule. To shift the deposition process into the energy deficient zone, the effective input power was decreased by pulsing at $25 \mathrm{~Hz}$ with a duty cycle varying from $10 \%$ to $100 \%$. The retention of C-O-C groups was highest for pulsing at $10 \%$ (power density and the Yasuda parameter was equal to $6.25 \mathrm{~mW} / \mathrm{cm}^{3}$ and $6.4 \mathrm{MJ} / \mathrm{kg}$ respectively). In these conditions the films were much more porous with a refractive index equal to $1.55 \pm 0.02$. A high retention level of ether groups on the coatings surface determines its antifouling properties [37, 41, 42, 43], thus pulsing of the input power is one of the ways to control the deposition process to have at the output coatings ranging from dense barrier to cell repellent soft antifouling coatings on demand.

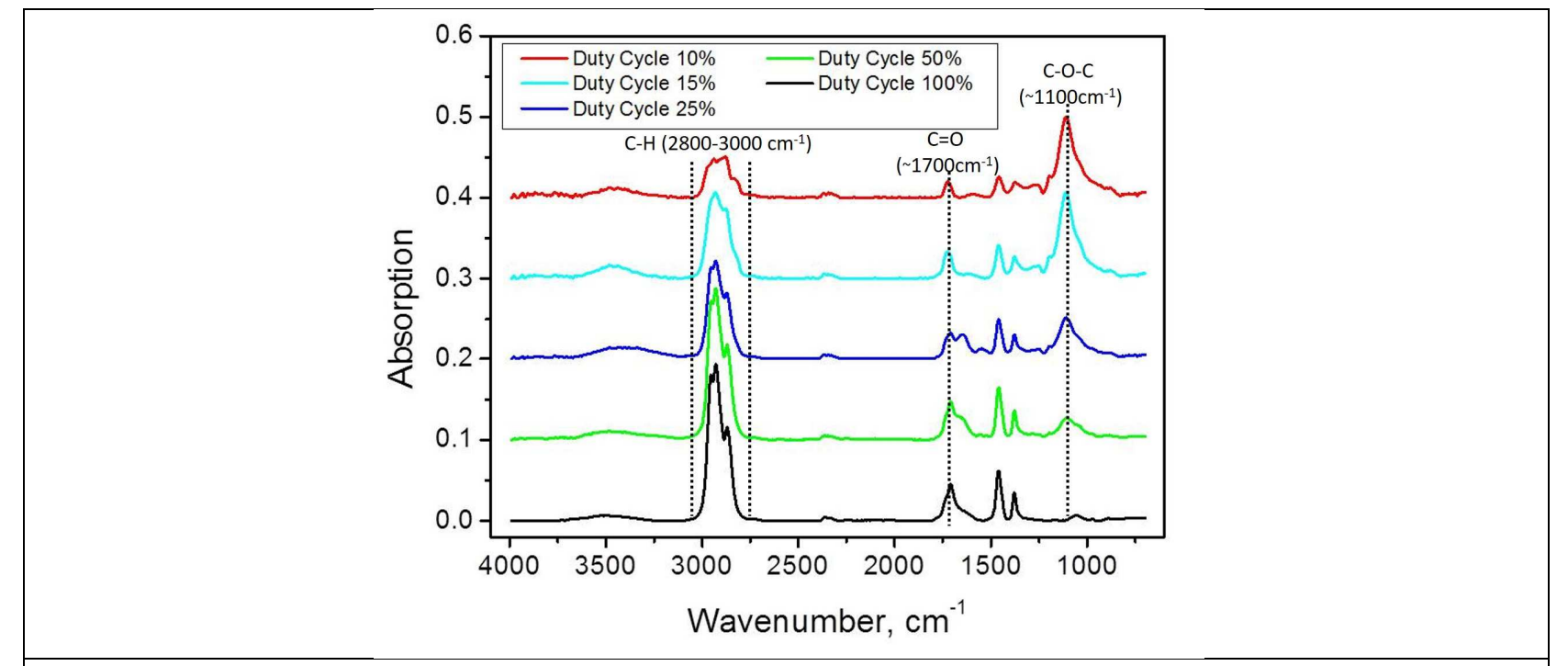

Fig. 4. FTIR spectra of films deposited from diglyme precursor at $25 \mathrm{~W}$ of input power but with different pulsing duty cycle: $10 \%, 15 \%, 20 \%, 25 \%$ and continuous at $100 \%$.

The collagen membrane (used as DDS support substrate) originates from porcine collagen that swells when introduced into the aqueous medium. The collagen membranes increase 5 times of its original thickness during the swelling process. The increase of the surface area is more crucial as it induces additional stress on the barrier layer and strongly affects its integrity and ability to control kinetics of release. The increase in the surface area of collagen membrane was recorded by optical microscope and subsequently images were analysed with Image software to calculate the surface area variation (fig. 5). This experiment was carried out only once to qualitatively examine changes of the surface area in respect to the exposure time to aqueous mediums. The swelling of the collagen leads to the formation of cracks of the barrier coating deposited on top of the membrane and induces a burst release of the encapsulated drug. The burst release of the drug at the beginning of the exposure of the DDS to the medium is considered as a desirable feature from the therapeutic point of view. However it is difficult to 
control the kinetics of the burst and for different samples the amount of drugs released in a burst mode was different.

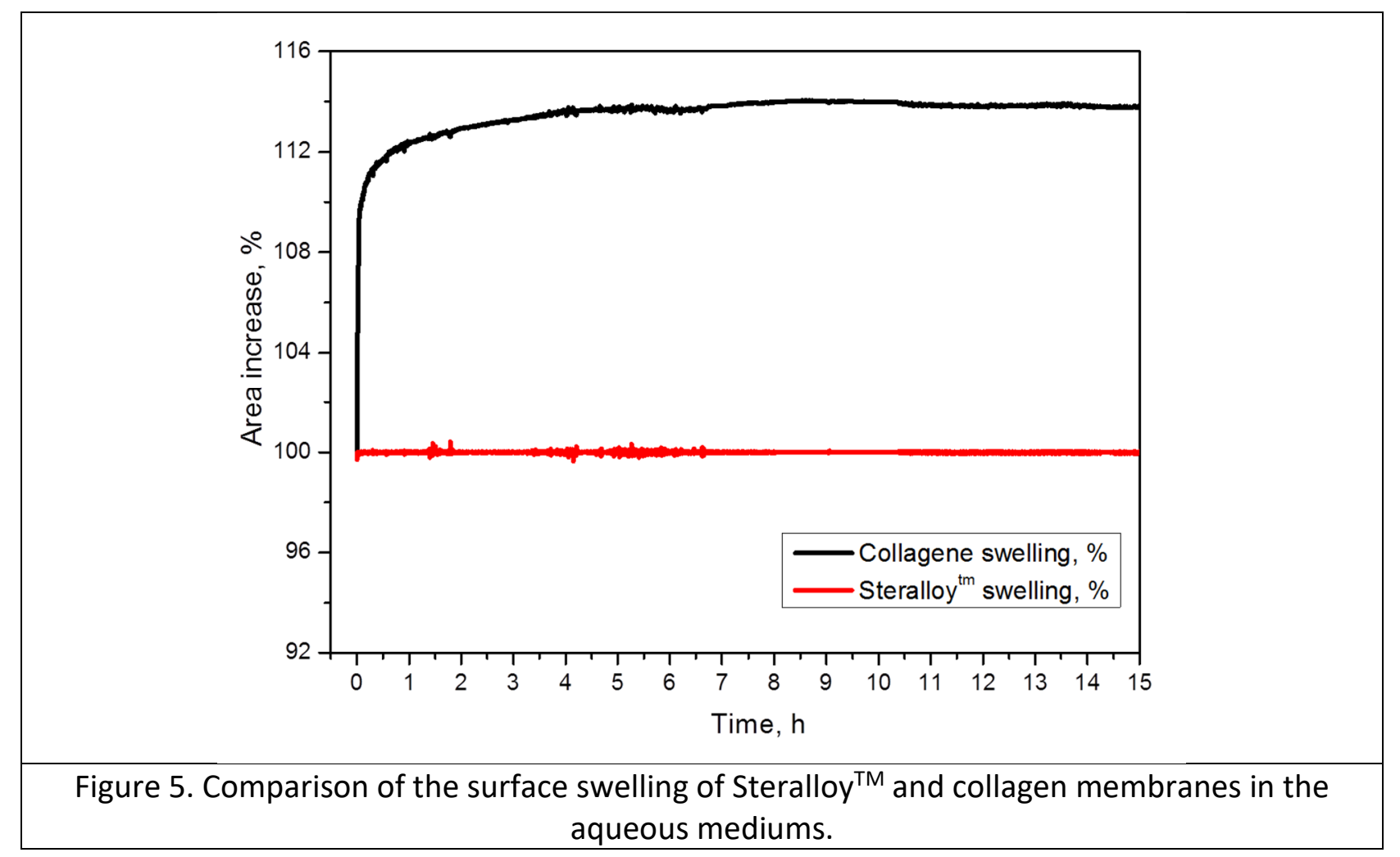

In fig. 6, a) SEM images of the formed microcracks on the barrier coating after swelling of collagen are illustrated. Further mechanical stress during handling and positioning of the membrane can lead to the growth of microcracks and delamination of the barrier coating (fig. $6, b)$.

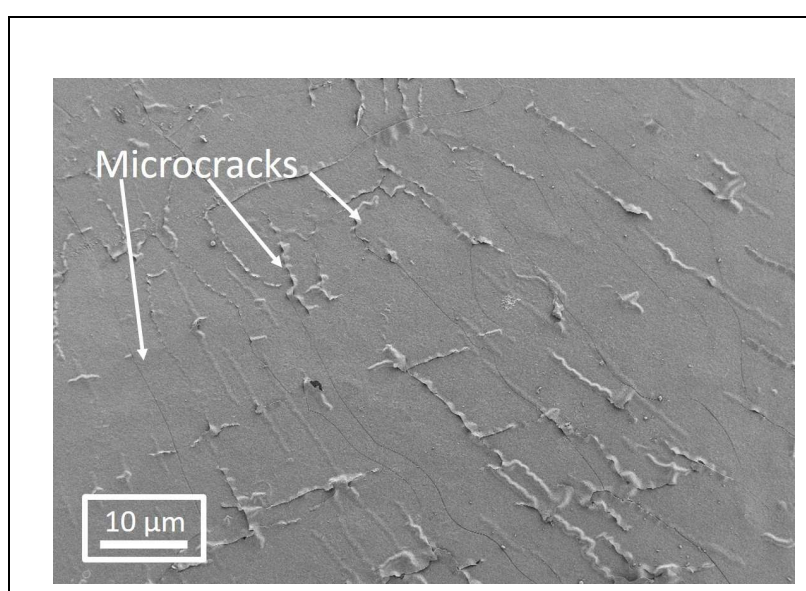

a)

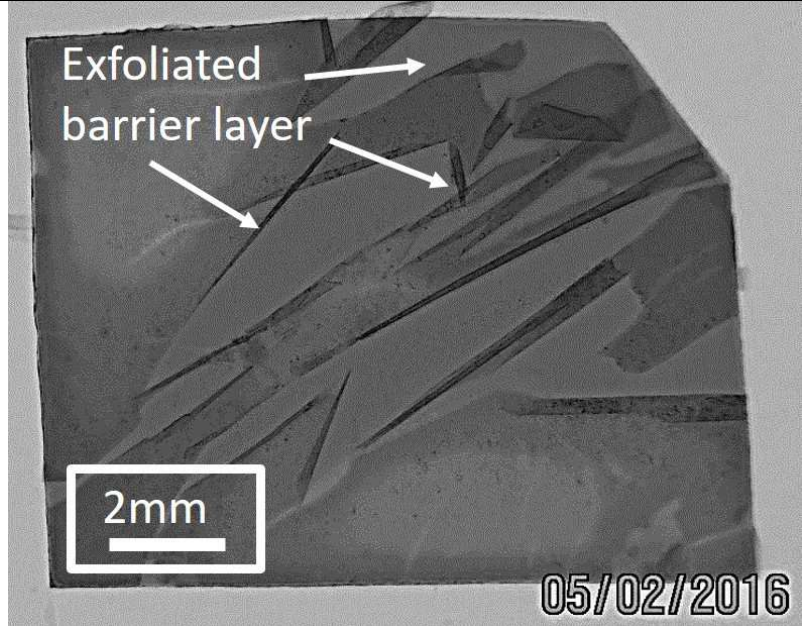

b)

Fig. 6. Microcracks formed on the surface of barrier coating on swelled collagen membrane a) and leading to delamination $b$ ).

Plasma polymers unlike polymers prepared by conventional methods accumulate high internal stress due to the mechanism of growth $[44,45]$. The internal stresses of thin coatings is easy to observe on flexible substrates, as later tend to curl during and after the deposition process. By 
the diameter of bended membrane it is possible to evaluate how much stress is accumulated in films. In order to reduce internal stresses of the barrier films and therefore the formation and progression of microcracks, we used the approach of depositing multi-layer coatings with alternating "soft" and "hard" layers, by varying the duty cycle of the pulsing during the deposition process [46]. A layer of a "soft" film acts as cushion and prevents "hard" barrier layer to accumulate more internal stress. Also decreasing the thickness of each hard coating reduces the sheer stress induced by bending of the films. Such films show good results and this approach was used for samples prepared in the following experiments. SEM image of multilayer barrier coating is illustrated in fig 7. Deposition rate of plasma polymerized "hard" coating (at continuous input power) was $15 \mathrm{~nm} / \mathrm{min}$ and for "soft" coating $4 \mathrm{~nm} / \mathrm{min}$ respectively. To deposit composite barrier film illustrated in fig 7 it took $7.5 \mathrm{~h}$ in total with 60 layers of alternating $40 \mathrm{~nm}$ "soft" and $60 \mathrm{~nm}$ "hard" coatings layers.

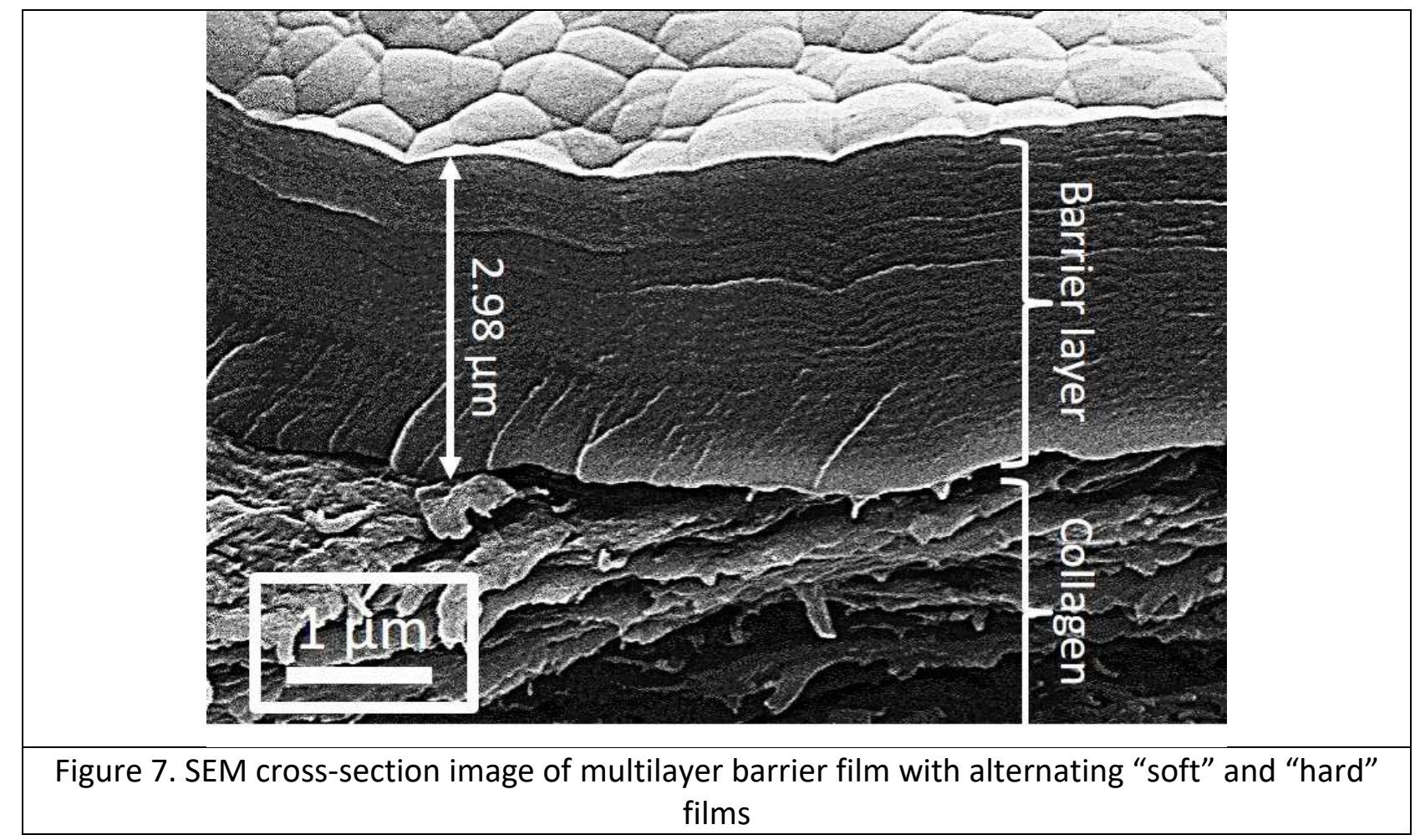

To measure the effectiveness of the plasma polymerized dense coatings as barrier layer, the kinetics of drug release was measured for MB and Carboplatin. $100 \mu \mathrm{g}$ of MB was sandwiched within the barrier coatings on the surface of collagen membrane and placed in $2 \mathrm{ml}$ of medium, and the concentration of $\mathrm{MB}$ in the medium was measured by following the absorption peak of $M B$ in the visible range $(665 \mathrm{~nm})$. In fig. 8, a) MB leaching kinetics over the exposure time is presented in log scale for different thicknesses of the barrier layer. For all samples two stages with different kinetics were observed. During the first 4 hours an intense leaching out followed by a lower release of MB. This burst in the beginning could be explained by the swelling of collagen substrate which tends to swell. In comparison samples prepared on Steralloy membranes (fig. 8, c) show no such behaviour, and better barrier properties could be achieved with thinner coatings due to non swelling nature of the substrates. In fig. 8, b) the carboplatin $(300 \mu \mathrm{g}$ ) release through $1 \mu \mathrm{m}$ thick barrier film and its accumulation in DMEM medium ( $2 \mathrm{ml}$ ) was measured by ICP-MS. Similar to the case of MB release kinetics, a two stage release was observed i.e. a burst stage followed by a more steady release. For a $1 \mu \mathrm{m}$ thick barrier film 
encapsulated $M B$, the total release ( $100 \%$ of the initial value) was observed in 50 days, whereas for carboplatin in 10 days. In this DDS model the degradation of the barrier coating wasn't observed during the experiments, and thus it was assumed that the release of the drug occurs in diffusion mode. Furthermore, we can assume that carboplatin as a denser and smaller in size molecule compared to $\mathrm{MB}$ have faster diffusion through the barrier layer and have higher release kinetics which we observe in our experiments [47]. Authors want to remark here that each of these experiments were carried out once to qualitatively compare different substrates to identify the best candidate for DDS supporting material.

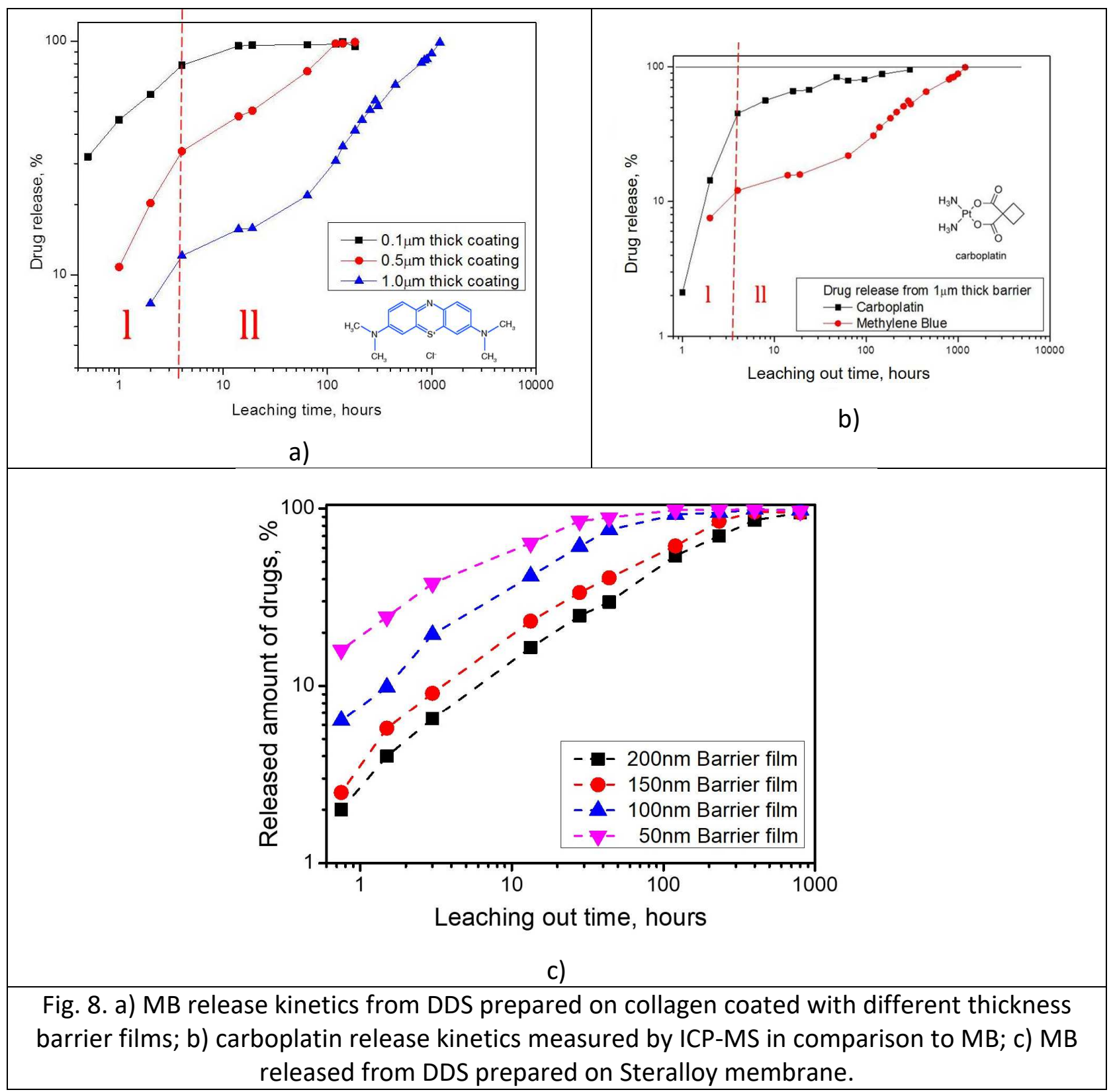

\section{Conclusion}

Low pressure PECVD approach to deposit functional coatings for biomedical devices was used to deposit both barrier layers and coatings with retention of functional groups of the used precursor. The deposition parameters of ICP plasma were optimized for fabrication of DDS with dense (monomer-deficient) coatings at $64 \mathrm{MJ} / \mathrm{kg}$ and soft (energy-deficient) coatings at 6.4 
$\mathrm{MJ} / \mathrm{kg}$ from diglyme precursor. Two commercially available biocompatible patches were considered as supporting membranes for DDS, and based on the stability of drug release kinetics it was shown that Steralloy membranes were the preferred choice. In this work bases for further research and development of plasma polymerized DDS for biomedical application was made to follow up with in vitro and in vivo experiments.

\section{Acknowledgements:}

The authors would like to acknowledge INSERM for having funded the project CORAPLAS (Controlled Release of Antineoplastic Drug from Low and Atmospheric Pressure Plasma Polymerized Biodegradable Coatings for Oncological Application), Project ID PC201404. Also we are grateful to Dr. L. Nicole and Dr. C. Boissiere from LCMCP UPMC and D. Bricault and F. Pillier from LISE UPMC for assistance with ellipsometry and SEM-FEG measurements. 


\section{References}

[1] A. Covens, M. Carey, P. Bryson, "Systematic review of first-line chemotherapy for newly diagnosed postoperative patients with stage II, III or IV epithelial ovarian cancer," Gynecol. Oncol., vol. 85, p. 71-80, 2002.

[2] M.E. Gore, I. Fryatt, E. Wiltshaw, "Treatment of relapsed carcinoma of the ovary with cisplatin or carboplatin following initial treatment with these compounds," Gynecol. Oncol., vol. 36, p. 207-211, 1990.

[3] L. Kelland, "The resurgence of platinum-based cancer chemotherapy.," Nature Reviews Cancer., vol. 7, pp. 573-584, 2007.

[4] B. Rosenberg, L. VanCamp, J. E. Trosko and V. H. Mansour, "Platinum compounds: A new class of potent antitumour agents," Nature., vol. 222, p. 385-386, 1969.

[5] A. Eastman, " Activation of programmed cell death by anticancer agents: cisplatin as a model system," Cancer Cells, vol. 2, p. 275-280, 1990.

[6] J. Zhang, C.Q. Lan, M. Post, B. Simard, Y. Deslandes, T.H. Hsieh, "Design of nanoparticles as drug carriers for cancer therapy," Cancer Genom. Proteom., vol. 3, p. 147-158, 2006.

[7] Y. Zhang, H. F. Chan, K. W. Leong, "Advanced materials and processing for drug delivery: The past and the future," Advanced Drug Delivery Reviews, vol. 65, no. 1, pp. 104-120, 2013.

[8] M. Laroussi, "From Killing Bacteria to Destroying Cancer Cells: 20 Years of Plasma Medicine," Plasma Processes and Polymers, vol. 11, no. 12, p. 1138-1141, 2014.

[9] Z. Zhao, J. Wang, H.Q. Mao, K.W. Leong, "Polyphosphoesters in drug and gene delivery," Adv. Drug Deliv. Rev., vol. 55, pp. 483-499, 2003.

[10] Y.C. Wang, Y.Y. Yuan, J.Z. Du, X.Z. Yang, J. Wang, "Recent progress in polyphosphoesters: from controlled synthesis to biomedical applications," Macromol. Biosci., vol. 9, p. 1154-1164, 2009.

[11] G. Rath, T. Hussain, G. Chauhan, T. Garg, A. K. Goyal, "Development and characterization of cefazolin loaded zinc oxide nanoparticles composite gelatin nanofiber mats for postoperative surgical wounds," Mater. Sci. Eng. C, vol. 58, pp. 242-253, 2016.

[12] U. Aggarwal, A. K. Goyal, G. Rath, "Development and characterization of the cisplatin loaded nanofibers forthe treatment of cervical cancer," Mater. Sci. Eng. C, vol. 75, pp. 125-132, 2017.

[13] Norma A Alcantar, Eray S Aydil, Jacob N Israelachvili, "Polyethylene glycol-coated biocompatible surfaces," Journal of biomedical materials research, vol. 51, no. 3, pp. 343-351, 2000.

[14] A. Popelka, J. Kronek, I. Nová, A. Kleinová, M. Mičušík, M. Špírková, M. Omastová, "Surface modification of low-density polyethylene with poly(2-ethyl-2-oxazoline) using a low-pressure plasma treatment," Vacuum, vol. 100, p. 53-56, 2014.

[15] S.L. Bourke, J. Kohn, "Polymers derived from the amino acid L-tyrosine: polycarbonates, polyarylates and copolymers with poly(ethylene glycol)," Adv. Drug Deliv. Rev.,, vol. 55, pp. 447466, 2003. 
[16] J.M. Karp, R. Langer, "Development and therapeutic applications of advanced biomaterials," Curr. Opin. Biotechnol., vol. 18, p. 454-459, 2007.

[17] R. Langer, D.A. Tirrell, "Designing materials for biology and medicine," Nature, vol. 428, p. 487-492, 2004.

[18] S. Taschieri, S. Corbella, M. Saita, I. Tsesis, and M. D. Fabbro, "Osteotome-Mediated Sinus Lift without Grafting Material: A Review of Literature and a Technique Proposal," International Journal of Dentistry, vol. 2012, p. 9, 2012.

[19] R. Brustia, O. Scatton, O. Soubrane, "Variation on a Theme: Alternative to Plastic Bag in ALPPS Procedures: Feasibility and Clinical Safety of COVA+ ${ }^{\mathrm{TM}}$ Membrane in ALPPS Procedures," World Journal of Surgery, vol. 39, no. 12, p. 3023-3027, 2015.

[20] A. Baitukha, I. Al-Dybiat, A. Valinataj-Omran, J. Pulpytel, M. Pocard, M. Mirshahi, F. Arefi-Khonsari, "Low Pressure Plasma Processing of Collagen Membranes for Anti-Cancer," Journal of Material Sciences \& Engineering, vol. 7, no. 6, 2018.

[21] S. Bhatt, J. Pulpytel, M. Mirshahi, F. Arefi-Khonsari, "Catalyst-Free Plasma-Assisted Copolymerization of Poly( $\varepsilon$-caprolactone)-poly(ethylene glycol) for Biomedical Applications," ACS Macro Letters, vol. 1, no. 6, p. 764-767, 2012.

[22] S. Bhatt, J. Pulpytel, M. Mirshahi, F. Arefi-Khonsari, "Nano thick poly ( $\varepsilon$-caprolactone)-poly (ethylene glycol) coatings developed by catalyst free plasma assisted copolymerization process for biomedical applications," RSC Advances, vol. 2, pp. 9114-9123, 2012.

[23] E. Sardella, E. R. Fisher, J. C. Shearer, M. G. Trulli, R. Gristina, P. Favia, "N2/H2O Plasma Assisted Functionalization of Poly( $\varepsilon$-caprolactone) Porous Scaffolds: Acidic/Basic Character versus Cell Behavior," Plasma Processes and Polymers, vol. 12, no. 8, p. 786-798, 2015.

[24] K. S. Siow, S. Kumar, H. J. Griesser, "Low-Pressure Plasma Methods for Generating Non-Reactive Hydrophilic and Hydrogel-Like Bio-Interface Coatings - A Review," Plasma processes and polymers, vol. 12, no. 1, p. 8-24, 2015.

[25] E. Sardella, F. Palumbo, G. Camporeale, P. Favia, "Non-Equilibrium Plasma Processing for the Preparation of Antibacterial Surfaces," Materials, vol. 9, no. 7, p. 515, 2016.

[26] S. Yoshida, K. Hagiwara, T. Hasebe, A. Hotta, "Surface modification of polymers by plasma treatments for the enhancement of biocompatibility and controlled drug release," Surface and Coatings Technology, vol. 233, p. 99-107, 2013.

[27] H. Jeon, S. Koo, W. M. Reese, P. Loskill, C. P. Grigoropoulos, K. E. Healy, "Directing cell migration and organization via nanocrater-patterned cell-repellent interfaces," Nature Materials, vol. 14, pp. 918923, 2015.

[28] H. Muguruma, T. Hoshino, R. Fujita, T. Sumii, S. Kudo, "Adhesion and Alignment of Nonparenchymal Cells onto a Patterned Surface with a Two-Step Plasma Polymerization Process," Plasma Processes and Polymers, vol. 12, no. 8, p. 746-754, 2015.

[29] M. Vandenbosschea, L. Bernardb, P. Ruppera, K. Maniura-Weberc, M. Heubergera, G. Faccioc, D. Hegemanna, "Micro-patterned plasma polymer films for bio-sensing," Materials \& Design, vol. 114, pp. 123-128, 2017. 
[30] E. Sardella, R. A. Salama, G. H. Waly, A. N. Habib, P. Favia, R. Gristina, "Improving Internal Cell Colonization of Porous Scaffolds with Chemical Gradients Produced by Plasma Assisted Approaches," ACS Appl. Mater. Interfaces, vol. 9, no. 5, p. 4966-4975, 2017.

[31] S. Bhatt, J. Pulpytel, M. Mirshahi, F. Arefi-Khonsari, "Plasma Co-polymerized Nano Coatings - As a Biodegradable Solid Carrier for Controlled Drug Delivery Applications," Polymer, vol. 54, pp. 48204829, 2013.

[32] S. Bhatt, F. Valamanesh, J. Pulpytel, R. Lo Dico, A. Baitukha, I. Al-Dybiat, M. Pocard, F. ArefiKhonsari, M. Mirshahi, "Radio-frequency plasma polymerized biodegradable carrier for in vivo release of cis-platinum," Oncotarget, vol. 7, no. 36, pp. 58121-58132, 2016.

[33] S. Bhatt, J. Pulpytel, S. Mori, M. Mirshahi and F. Arefi-Khonsari, "Cell Repellent Coatings Developed by an Open Air Atmospheric Pressure Non-Equilibrium Argon Plasma Jet for Biomedical Applications," Plasma Processes and Polymers, vol. 11, p. 24-36 , 2014.

[34] S. H.Alavi, M. S. Baliarda, N. Bonessio, L. Valdevit, A. Kheradvar, "A Tri-Leaflet Nitinol Mesh Scaffold for Engineering Heart Valves," Annals of Biomedical Engineering, vol. 45, no. 2, p. 413-426, 2017.

[35] Y. Oulhote, B. L. Bot, J. Poupon, J. P. Lucas, C. Mandin, A. Etchevers, D. Zmirou-Navier, P. Glorennec, "Identification of sources of lead exposure in French children by lead isotope analysis: a crosssectional study," Environmental Health, vol. 10, no. 75, 2011.

[36] R. W. B. Pearse, A. G. Gaydon, The indentification of molecular spectra, London: Chapman \& Hall LTD, 1950.

[37] F. Palumbo, P. Favia, M. Vulpio, R. d'Agostino, "RF Plasma Deposition of PEO-Like Films: Diagnostics and Process Control," Plasmas and Polymers, vol. 6, no. 3, pp. 163-174, 2001.

[38] H.Y. Dai, X.R. Cheng, C.F. Wang, Y.C. Xue, Z.P. Chen, "Structural, optical and electrical properties of amorphous carbon films deposited by pulsed unbalanced magnetron sputtering," Optik, vol. 126, no. 7-8, pp. 861-864, 2015.

[39] H. Yasuda, "Glow discharge polymerization," Journal of Polymer Science: Macromolecular Reviews, vol. 16, no. 1, p. 199-293, 1981.

[40] D. Hegemann, E. Korner, S. Guimond, "Plasma Polymerization of Acrylic Acid Revisited," Plasma Processes and Polymers, vol. 6, no. 4, p. 246-254, 2008.

[41] F. Davis, "The origin of pegnology," Advanced Drug Delivery Reviews, vol. 54, no. 4, pp. 457-458, 2002.

[42] T. Jacobs, R. Morent, N. De Geyter, P. Dubruel, C. Leys, "Plasma Surface Modification of Biomedical Polymers: Influence on Cell-Material Interaction," Plasma Chemistry and Plasma Processing, vol. 32, no. 5, p. 1039-1073, 2012.

[43] Z. Ademovic, B. Holst, R. A. Kahn, I. Jørring, "The method of surface PEGylation influences leukocyte adhesion and activation," J Mater Sci: Mater Med, vol. 17, p. 203-211, 2006.

[44] D. Hegemann, H. Brunner, C. Oehr, " Evaluation of deposition conditions to design plasma," Surface and Coatings Technology, vol. 174, p. 253-260, 2003.

[45] S. Singamaneni, M. C. LeMieux, H. Jiang, T. J. Bunning, V. V. Tsukruk, "Negative Thermal Expansion 
in Ultrathin Plasma," Chem. Mater., vol. 19, pp. 129-131, 2007.

[46] D. Hegemann, "4.09 Plasma Polymer Deposition and Coatings on Polymers," in Comprehensive Materials Processing, Cameron, Elsevier, 2014, p. 201-228.

[47] P. Grathwohl, Diffusion in natural porous media: Contaminant transport, sorption / desorption and dissolution kinetics, Kluwer Academic, 1998. 